\title{
Editorial \\ Currículo escolar, processo educacional e constituição do sujeito no mundo contemporâneo
}

A presente edição é composta por um conjunto de dez artigos. Embora, aparentemente, os textos tratam de temáticas diversas, há um forte elo comum entre os mesmos. São temáticas de cunho paradigmático ou operacional que visam a explicitar e compreender, com base em pesquisas bibliográficas ou quantitativas, questões centrais que tematizam e dizem respeito ao processo e aos fundamentos da educação escolar,

No primeiro texto Direito à educação e o processo de ampliação do Ensino Fundamental, Simone Fátima Flach explicita as principais ações políticas e os dados da oferta da educação municipal do Ensino Fundamental de 9 Anos no município de Ponta Grossa/PR, no período de 2001 a 2008. Fundamentada em uma abordagem qualitativa, analisa os impactos sociais da ampliação do Ensino Fundamental e conclui que as ações e seus efeitos foram parciais e fragilizados, tendo em vista que o entendimento sobre o direito à educação para o ingresso nessa etapa da escolaridade ocorreu de forma diferenciada.

No estudo, Os diferentes sentidos atribuídos à compreensão da relação da Educação Profissional e Ensino Médio, as autoras Janice R. Cardoso Griebeler e Ireni Marilene Zago Figueiredo buscam identificar a polissemia dos termos que tratam sobre a relação da Educação Profissional com o Ensino Médio. A leitura de uma ampla literatura sobre a temática permitiu buscar a explicitação dos diferentes sentidos atribuídos à compreensão de duas expressões muito frequentes na relação Educação Profissional e Ensino Médio: a) articulação e integração e; b) Educação Profissional integrada ao Ensino Médio.

Iael de Souza, no artigo Da antropologia aos fundamentos antropológicos da educação - considerações iniciais, buscou compreender o homem como problema, em si e para si, sua humanização, formação e autoconstrução. Com enfoque no paradigma do materialismo histórico-dialético, analisa as possibili- 
dades e potencialidades da realização humana quando o homem se coloca como problema de si mesmo. A partir dessa questão crucial, o texto procura qual pode ser a natureza essencial da educação, o seu sentido amplo e seu fundamento antropológico no contexto do modo de produção e vida capitalista.

Em seu estudo bibliográfico, Josiane Peres Gonçalves analisou o processo de desenvolvimento humano, destacando as diferentes fases da vida bem como a idade e as principais características de cada fase. Com o título Ciclo vital: início, desenvolvimento e fim da vida humana, possíveis contribuições para educadores, a autora aponta a dificuldade de estabelecer padrões para a vida humana tendo em vista que fatores culturais e sociais exercem muitas influências em cada pessoa, além de outros aspectos que ocorrem em populações de sociedades ocidentais industrializadas. A autora analisa desde a questão do desenvolvimento, passando pela concepção e período pré-natal, as fases correspondentes à infância, adolescência e idade adulta, incluindo o idoso, para, finalmente, refletir sobre a morte que marca o fim do ciclo vital.

No texto As práticas pedagógicas dos professores da Educação Básica na interação com os livros didáticos digitais, Eliane Mimesse Prado analisa a interação das práticas pedagógicas dos professores da educação básica com os livros didáticos digitais. Com base em uma pesquisa de campo entre professores que lecionam em escolas de grande porte, na rede privada da cidade de Curitiba/ PR, o objetivo da autora foi verificar quais os usos cotidianos dos livros didáticos digitais nas salas de aula. $\mathrm{O}$ resultado da pesquisa indica que o livro didático digital ainda não atingiu plenamente as práticas pedagógicas dos professores.

No texto, Habilidades de professores e estudantes da educação básica no uso das TICs como ferramentas de ensino e aprendizagem: notas para uma prática pedagógica educomunicativa. Caso Florianópolis 2013/2014, Ademilde Silveira Sartori, Elias Said Hung e Patrícia Justo Moreira apresentam reflexões baseadas em análises de dados parciais referentes ao município de Florianópolis/ $\mathrm{SC}$, coletados junto a estudantes de sexto ano e professores dos anos finais do Ensino Fundamental das escolas vinculadas à Rede estadual ou à Rede municipal pública de ensino, situadas na cidade de Florianópolis/SC, entre 2013 e 2014. A pesquisa buscou identificar as habilidades pedagógicas no uso das TICs 
por parte de professores e estudantes e conclui sobre a necessidade de planejar políticas públicas que auxiliem no aprofundamento do uso pedagógico das TICs na educação pública a partir das habilidades necessárias para este segmento.

No artigo Projeto Pedagógico, Abordagem Pedagógica e Cenários de Prática: avaliação de tendências de mudanças em cursos da área da saúde, Kênia Alessandra de Araújo Celestino, Nilce Maria da Silva Campos Costa, Ida Helena Carvalho Francescantônio Menezes e Lucilene Maria de Sousa, expõem as tendências de mudança em cursos de Graduação da área da saúde da Universidade Federal de Goiás, tendo como base os aspectos preconizados pelas Diretrizes Curriculares Nacionais. Trata-se de um estudo descritivo cuja coleta de dados foi realizada em reunião com docentes, discentes e servidores técnico-administrativos dos cursos de Enfermagem, Farmácia, Medicina e Nutrição, no período de 2013 e 2014. A pesquisa observa que todos os cursos estão em processo de mudança dos projetos pedagógicos, das abordagens pedagógicas e dos cenários de prática, conforme previsto pelas Diretrizes Curriculares Nacionais.

As autoras Indman Ruana Lima Queiroz e Elisa Prestes Massena, no artigo Reflexões acerca de compreensões de currículo de professores em exercício, apresentam compreensões de currículo de professores em exercício de escolas públicas da Região Nordeste do país. O universo da pesquisa foram dez professores de duas cidades nordestinas. Os resultados mostraram que as compreensões de currículo de muitos professores ainda estão ancoradas nos conteúdos propostos pelo livro didático e também pelo que é exigido nos exames de acesso ao Ensino Superior. Segundo as autoras, isso pode ser consequência de como as discussões de currículo ocorrem nos cursos de formação inicial e indicam a necessidade da formação continuada desses sujeitos.

No artigo Trabalho e educação na modernidade líquida: reflexões sobre práticas pedagógicas contemporâneas, João Paulo Baliscei, Geiva Carolina Calsa e Vinícius Vinícius Stein indicam que, na contemporaneidade, as relações e exigências de trabalho são distintas daquelas de outrora. Apresentam o resultado de uma pesquisa bibliográfica fundamentada nos Estudos Culturais e tecem considerações a respeito do trabalho e da educação no século 21. Segundo os autores, os aparatos tecnológicos e suas constantes inovações e aperfeiçoamentos 
demandam que os trabalhadores e trabalhadoras sejam flexíveis e que aprendam com rapidez. Concluem que, enquanto o mercado de trabalho tem acompanhado o ritmo das inovações, a escola e as práticas pedagógicas apresentam poucas modificações em sua organização e currículo. Segundo os autores, a escola pode atender às demandas do trabalho desde que considere também as necessidades de uma formação estética, ética e política.

Roque Strieder e Clenio Lago, no texto Dispositivos de captura: profanação possível via formação de professores, analisam o contexto político contemporâneo. Para os autores, o atual contexto é fortemente marcado pela presença de dispositivos de captura de subjetividades e por um viés biopolítico que reduz a vida a objeto de cálculos, objeto de técnicas de vigilância e controle. Desde cenário, a reflexão tem como propósito tensionar de que modo e com quais estratégias, processos formativos podem fazer frente a essa subserviência aos dispositivos de captura das subjetividades. Apresentam como suporte da investigação e pano de fundo epistemológico a teoria da complexidade.

A partir deste conjunto de publicações, esperamos contribuir com as reflexões e discussões acerca de temáticas tão relevantes para a compreensão do currículo escolar, do processo educacional e da constituição do sujeito no mundo contemporâneo.

Maria Cristina Pansera-de-Araújo

Maria Simone Vione Schwengber

Celso José Martinazzo

Solange Castro Schorn 